\title{
PAST, PRESENT AND FUTURE OF WIND ENGINEERING
}

\author{
Alan G. Davenport ${ }^{1)}$ \\ 1)Boundary Layer Wind Tunnel Laboratory, The University of Western Ontario, \\ Faculty of Engineering Science, London, Ontario, Canada N6A 5B9
}

\section{INTRODUCTION}

It is a great honour for me to be invited to present a perspective on the evolution of wind engineering. I will try to do so by presenting some images of the wind and allowing the wind to speak for itself.

The past half century - this being an appropriate period for retrospection - has witnessed some remarkably interesting developments in the treatment of wind loading in structural design. During this time the description of wind load has moved from relatively simple, straightforward, notions of static drag forces to much more sophisticated models, involving all the manifold questions of climate, meteorology, aerodynamics, structural mechanics and dynamics and, more recently, reliability. It is worth reflecting on some of these changes and why they happened.

Fifty years ago - during the 1950's - structures were, by present standards relatively massive. Structural members themselves were heavier due to the relatively weak materials, and dead loads were higher due, for example, to the heavy masonry and stone facades on buildings, and the use of heavy, reinforced concrete deck systems on bridges. These massive structures were frequently much stiffer than they were predicted to be due to the participation of the non-structural components, the contribution of which was difficult to estimate. The massiveness of these structures did little to emphasize the importance of wind forces - in questions of overturning for example - and effectively disguised the latent dynamic problems which were later to become important.

Wind loads were formulated along simple lines as the product of the velocity pressure, $1 / 2 \rho V^{2}$, and an aerodynamic coefficient related either to the drag $\left(C_{D}\right)$ or the local pressures $\left(C_{p}\right)$. The wind speed, $V$, was commonly based on the highest recorded gust wind speed (or some other convenient measure) and some allowance was made for the increase of wind speed with height, normally based on open country conditions. The drag and pressure coefficients were derived from uniform flow tests in aeronautical wind tunnels. The very simple rules for wind loading which resulted were sometimes streamlined further to obviate unnecessary calculations; an example was the New York City code, in which wind loads below $200 \mathrm{ft}$. were ignored and were only $20 \mathrm{lb} / \mathrm{ft}^{2}$ above this height. The $33 \%$ increase in design stress under wind action, commonly allowed by codes, may have had similar origins.

The sky-scraper boom of the 1930's and later in the 1960's resulted in an active interest in wind forces and an appreciation of the merits of stiffness (expressed through the deflection criteria). There was a growing curiosity in, and awareness of, vibrations partly through instrumental records, and partly through human perception of the motion - occasionally discomfort. During the 1930s Rathun ${ }^{1}$ made 
extensive observations on the Empire State Building and stated that in wind it vibrated 'like the tines of a tuning fork'. Little it seemed could be done about it. In Spurr's ${ }^{2}$ treatise on Wind Bracing he stated 'the whole question of the vibration in buildings from the effects of variable wind pressures is complicated by the indeterminate nature of the pressures themselves, as well as by the great variation in size, shape, weight, height and location of buildings'.

Wind tunnel testing at this time was mostly carried out in aeronautical wind tunnels in smooth uniform flow. There were some isolated exceptions by Flaschbart ${ }^{3}$, Irminger and Nokkentved ${ }^{4}$ and by Bailey and Vincent ${ }^{5}$ at the NPL in which the variation of wind speed with height was simulated. Although there were significant differences in the pressures between uniform and boundary layer flow, it appeared to be of academic interest only. Bailey and Vincent undertook some valuable full scale measurements of pressures on low buildings which confirmed the wind tunnel boundary layer but not the smooth flow measurements.

In summary, the picture we get of wind loading in the 1950's is one in which the massiveness of the structure minimized its effects. The description was kept extremely simple (and static). The research into areas which might have challenged these simple notions - into the dynamic response to wind for example - was still inconclusive.

In tracing the further developments of wind loading from the 1930's to the present there appear to have been several forces at work. First there have been some radical changes in structural properties - mass, stiffness and damping. The average densities of tall buildings and long span bridges, for example, have fallen by roughly a factor of $2-$ from around $20 \mathrm{lb} / \mathrm{ft}^{3}$ to $10 \mathrm{lb} / \mathrm{ft}^{3}$ in the case of buildings, and from $200 \mathrm{lb} / \mathrm{ft}^{2}$ to 100 $\mathrm{lb} / \mathrm{ft}^{2}$ of roadway in the case of long span bridges. In parallel, the substantial increases in material strengths (by factors of 2 and 3 in the cases of structural steel and concrete) has led to reductions in member sizes and consequently stiffness; this has been exaggerated further by the omission of heavy masonry cladding and frame infill and the loss therefore of their contributions to stiffness. To this we can add the significant improvements in analysis such as plastic analysis ${ }^{6}$ and the contributions of the digital computer. Lastly there have been significant reductions in damping due to extensive use of welding, pre-stressing and the omission of heavy masonry elements. (This led to Southwell ${ }^{7}$ to remark, prophetically, at a Colston Research Society meeting in 1949, that the endowment of structures with damping would become an urgent problem for the future). All of these changes in structural form, it turns out, directly increase their susceptibility to wind and hence the need for better models of wind loading. By the 1960's the dynamic behaviour had become a limiting factor with tall buildings as had happened earlier with bridges.

A second factor in the development of the current approaches to wind loading was what can be described as osmosis from other fields particularly meteorology and aeronautical engineering. For example, the meteorological study of wind in the atmospheric boundary layer by Taylor ${ }^{8}$, Sutton' and others was of obvious importance in the study of wind loading. The direct parallels between aircraft flutter and bridge flutter were pointed out by von $\operatorname{Karman}^{10}$, Farquharson ${ }^{11}$, Pugsley ${ }^{12}$, Scruton ${ }^{13}$, Hirai ${ }^{14}$, Okubo $^{15}$, Konishi and Shirashi ${ }^{16}$, Ishizaki ${ }^{17}$ and others.

A third factor was the stimulus provided by some dramatic failures. The Tacoma Narrows Bridge was the notable example, but other large bridges, the Golden Gate included ${ }^{18}$, survived some hair-raising episodes of aerodynamic instability. Twenty-five years later the collapse of the Ferrybridge cooling towers provided a similar spur to research efforts ${ }^{19}$. Theodore von $\mathrm{Karman}^{10}$, who was involved in the past mortems of the Tacoma Bridge drew attention to the dynamic problems in the following uncomplimentary terms:

'I hadn't reckoned on the depth and long standing of the prejudices of bridge engineers. Their thinking was largely influence by consideration of 'static forces' like weight and pressure which create no motion instead of 'dynamic forces' which produce motion or changes of motion. Bridges had been observed to oscillate in the wind before, but nobody had thought such motion important. Bridge failures were usually blamed on other things' 
A highly significant development during the 1950's was due to Jensen ${ }^{20}$. He undertook a comparison of the mean pressures on small buildings in full scale and in wind tunnel model experiments. These were carried out in a variety of boundary layers, each characterized by the roughness length, $z_{o}$. Jensen's experiments showed that when the parameter $h / z_{o}$ was the same ( $h$ being the building height), the full scale and model results agreed. From this Jensen stated his model law:

'The correct model test for phenomena in the wind must be carried out in a turbulent boundary layer and the model law requires the boundary layer to be scaled as regards the velocity profile.'

The extension of Jensen's essential concept beyond the time-averaged effects to considerations of the fluctuations of velocity and pressures and of the turbulence scales was the next important stage. Outstanding leadership in the area of boundary layer wind tunnel techniques was provided by Cermak, Plate, Davenport and others.

During the 1950's the study of wind loading was ready to explode. Research ideas in different fields had been ticking away for several decades. Structures were becoming higher, more flexible, less damped and larger and for each of these reasons, wind was becoming a more critical question; the dramatic failures provided the necessary spark.

Through the work of Ackeret $^{21}$, Farquharson ${ }^{11}$, Frazer $^{13}$, Jensen ${ }^{20}$, Scruton ${ }^{13}$, Sherlock ${ }^{22}$, Vincent $^{18}$, Hirai ${ }^{14}$, Simiu and Scanlan ${ }^{23}$ and many others, the field of wind engineering started to gather momentum and was dragged forward by the developments in structural engineering. Since that time the field has expanded rapidly with all the signs of a divergent instability. The growing literature is well documented by proceedings of international conferences - those related to wind engineering for both buildings and bridges, transmission lines, chimneys, offshore platforms and many other wind sensitive types. To discuss the present we need wide angle lens.

\section{THE PLANET AND THE WIND}

Viewed from space - or standing on the moon the atmosphere of planet earth seems a thin layer, not much thicker than the highest roughness element of the earth's surface - Mount Everest, roughly $1 / 2500$ of the earth's diameter. As the earth rotates, the diurnal cycles of radiation from the sun heat different regions of the atmosphere. The clouds reflect some of this heat away from the earth; some is trapped by greenhouse gases. Heat is exchanged in the oceans through powerful thermal currents such as the gulf stream, and $\mathrm{El}$ Nino, which act as conveyor belts for concentrations of heat. Relatively small amounts of green house gases provide a window for the heat to be radiated away. Their influence is powerful; and without this window the earth's temperature would plummet and the oceans freeze. The wind is part of this circulation of the atmosphere. This is home for all of us.

\section{SCALES OF TURBULENCE AND MIXING}

An all important process in the atmosphere is mixing. This happens at all scales from those of the weather systems, to those of tropical cyclones and intense local storms such as tornadoes, thunderstorms and down bursts. Mixing of the faster moving air at the equator with the slower moving air at the mid latitudes causes the trade winds and the westerlies. This mixing continues down to scales of the atmospheric boundary layer and even further at the scales of turbulence and of the Kolmogoroff inertial sub-range of motions and of viscous energy dissipation. These eddying motions are fundamental characteristics of the atmosphere of significance to the wind engineer. An excellent summary has been provided by Hunt and Morrison ${ }^{24}$.

\section{GREENHOUSE EFFECTS AND CLIMATE CHANGE}

Changes in the carbon dioxide content through human intervention have the potential to change the planet's circulation patterns - for better or for worse. One of the consequences may be the increase in climate extremes. These increases in extremes are important from the wind engineering viewpoint because, currently, wind related disasters are the most costly in terms of property damage and casualties. They are doubling roughly ever 5 - 10 years. The wind can provide power for windmills and sailing ships but can also cause catastrophic destruction. Wind engineering 
is vitally concerned with these interactions with human activities.

\section{THE GODS OF WIND}

Cultures round the world have in history developed a respect for wind and the powerful forces it unleashes. For some this is expressed through gods of wind. One of the most fearful of these is Fujin, the Japanese god of wind. He can be seen in the famous seventeenth century painting by Tawaraya - Sotatsu at the Kenninji Temple in Kyoto, racing through the heavens with a fierce look in his eyes and a bag of wind over his shoulder which from time to time he lets go. Perhaps he was the forerunner of the great Japanese wind engineering pioneers - like Professor Hirai of the University of Tokyo, Professor Ishizaki and Mitsuta of the Disaster Research Centre in Kyoto and others of today. There are others - Ehekatanatiu in Mexico; and the Wind Blowers in Canadian and North American cultures.

\section{WIND EFFECTS IN NATURE}

It is interesting to consider the effects of wind in nature. Palm trees, for example exhibit a remarkable adaptation to resisting strong winds such as hurricanes. Over the millennia they have developed a remarkably tough, fibrous, trunk with excellent fatigue resistance. By furling their branches they reduce wind resistance so that their drag coefficient reduces dramatically with increase in the wind speed. This is a strategy not yet perfected by engineers. These trees also exhibit two highly efficient forms of vibration damping - structural damping through their trunk and aerodynamic damping through the fan action of their leaves as the palm tree sways. One could go on to talk about the benefits of the coconuts in shedding mass and aiding replacement, but I will leave that for another time. In contrast humans confront the wind by leaning forward into wind and relying on gravity!

\section{EARLY WIND ENGINEERING}

Experience during the early nineteenth century with long span bridges and tall towers made structural engineers conscious of wind forces. Telford's Menai Straits bridge, Brown's Brighton Chain pier, and Ellet's Wheeling bridge all failed due to wind action. Some bridges failed under vibration due to instability. Investigation of the wind forces were pioneered by Baker for the Firth of Forth bridge in Scotland, and by Gustaf Eiffel for the Eiffel Tower. Irminger in Denmark initiated wind tunnel testing on simple building shapes. These were some of the early beginnings of wind engineering. I have eluded to this earlier.

\section{THE WIND LOADING CHAIN ${ }^{25}$}

Some years ago the writer suggested that the key responses of a structure to wind forces could be summarized in terms of a chain of roughly five links or factors. We called it the "wind loading chain". The links making up this chain can be connected as follows:

1. $\{q\}$, is a climatic factor providing statistical information on a reference wind velocity pressure, direction and recurrence interval, and reflecting the storm systems which prevail in the region;

2. $\left\{C_{e}\right\}$, is an exposure factor defining the modifying influence of terrain roughness and topography on the wind velocity pressure;

3. $\left\{C_{p}\right\}$, is an aerodynamic shape factor describing the effect of geometric shape and leakage on the local pressures on the structure;

4. $\left\{C_{i}\right)$, is an influence factor which defines the ratio of the global responses $\{r\}$ of the structure to the local wind pressures acting over the exterior and interior surfaces of the structure;

5. $\left\{C_{a}\right\}$, is a dynamic amplification factor describing the influence of resonance and other forms of dynamic magnification on the key global responses.

The global responses can then be written

$$
r=q \cdot C_{e} \cdot C_{p} \cdot C_{i} \cdot C_{a}
$$

Ideally the factors forming the links in the chain can be specified exactly. For every structure there is a set of critical responses consisting of drag, lift and lateral loads, bending moments, shear forces, axial thrusts, torques, as well as the deformations, and buckling capacities. Definition of the influence functions for these responses opens the door to an efficient method of defining the structural responses and the design needs of individual members. 


\section{THE CHAIN OF UNCERTAINTIES OF THE WIND FORCES}

The traditional approach to the definition of wind loading chain has been to assume that the forces are deterministic. In fact they are in reality stochastic and statistically independent. In the simplest model the factors are represented by mean values and coefficients of variation. This constitutes a " second moment reliability" formulation. The mean and coefficient of variation of the responses can be written as:

$$
\bar{r}=\bar{q} \cdot \bar{C}_{e} \cdot \bar{C}_{p} \cdot \bar{C}_{i} \cdot \bar{C}_{a}
$$

and

$$
V_{r}^{2}=V_{q}^{2}+V_{c e}^{2}+V_{c p}^{2}+V_{c i}^{2}+V_{c a}^{2}
$$

If the capacity of the element impacted by the response $r$ is denoted $\bar{c}$ with mean value $\{\bar{c}\}$ and coefficient of variation $V_{c}^{2}$ we can use second moment reliability theory to determine a load factor and resistance factor. The design algorithm is then:

$$
\{c\} \cdot \exp \left(0.8 V_{c} B\right)>\{r\} \cdot \exp (-0.8 V r B)
$$

In this $B$ is a "safety index" and related to the probability of failure. Generally its value is around 3-5.

This procedure leads to a consistent treatment of the uncertainties for each critical member and load factor requirement. One of the sources of greatest uncertainty is the consistency between model and full scale. A variety of models are available to the wind engineer - ranging from simple static load modeling, to sophisticated dynamic boundary layer wind tunnel modeling and models using computational fluid dynamics. All have their uncertainties and errors. The question that must be asked is how large are the uncertainties. The opportunities for answering this question in advance are very different for building structures compared to other technologies such as aircraft and ship building. We need to take advantage of opportunities for verification when they arise. Brief comments on two such model/full scale comparisons conclude this lecture. They relate to the Golden Gate Bridge and the Empire State Building. Both these structures were trendsetters, and the largest in their day. With both, wind played an important role.

\section{THE GOLDEN GATE BRIDGE IN THE WIND $^{26,27,28,29}$}

The Golden Gate Bridge was built in 1937 and designed for static wind loading. In 1940 after the failure of the Tacoma Narrows bridge there was renewed interest in its dynamic behaviour in wind and the bridge was fitted with vertical and torsional accelerometers. The bridge was found to oscillate in two characteristic modes: a fundamental symmetric vertical buffeting mode with a frequency of $0.13 \mathrm{~Hz}$. and a fundamental anti-symmetric torsional mode with a frequency of $0.145 \mathrm{~Hz}$, which indicated aerodynamic instability (this was only observed once in 1952). Several wind tunnel models were built. These included a section model tested in smooth flow; a taut strip model tested in several intensities of uniform turbulence; and a scale taut strip model in turbulent flow which included the steep, prominent topographic features of the mountains to the north and south of the "gateway". These mountains shielded the northerly half of the span reducing the mean wind speed and increasing the turbulence intensity. The most convincing reproduction of the response was given by the smallest model which included the topography.

\section{THE EMPIRE STATE BUILDING AND THE WIND}

One of the turning points in wind engineering was the study undertaken for the towers of The World Trade Center ${ }^{30}$. This broke new ground in wind engineering in several respects. Tests were carried out in turbulent boundary layer flow. For this purpose wind tunnels at Colorado State University, The National Physical Laboratory in the U.K. and The Boundary Layer Wind Tunnel Laboratory at the University of Western Ontario were used. The models of the structure were dynamic not static and took account of the structural damping. Measurements focused not only the structural responses and the external fluctuating pressures on the glass but also the sway accelerations affecting the comfort of occupants. The evaluation of the wind climate was more detailed. None of these questions had been examined in detail before. The study was 
undertaken at a time when the Codes of Practice were simplistic and based on static pressures (for example 20 pounds per square foot for New York). The contrast between the static and dynamic pressures and responses was highly significant. Three primary sources of dynamic response were identified, the buffeting by gusts in the approaching flow, the buffeting by vortices in the wake of the structure and the aerodynamic damping forces due to the motion of the structure through the wind. At this stage in the development full scale verification of the new design assumptions was very important.

Some valuable full scale validation of these results was obtained shortly after using the so called "base balance" modeling of The Empire State Building the tallest building prior to The World Trade Center. Full scale modeling had been undertaken by Rathbun in the 1940's. In this instance the full scale evidence of behaviour was derived from the measurement of the sway of a plumb bob suspended from the $86^{\text {th }}$ floor to the base of the building while the wind speed was measured from an anemometer on the air-ship mooring mast. Information on the mass moment of inertia and estimates of the frequencies of vibration in the east west and north south directions and gave information on the stiffness in a linear mode shape of vibration. This enabled the base bending moment coefficient to be estimated and compared with the same quantities derived in the wind tunnel. The results were well within the margin of error. Comparison was also good for the estimated maximum long term acceleration over a ten year period being of the order of $4-8$ milli-g. This result was a useful benchmark. Comparison of the full scale and model behaviour is vital in establishing confidence that wind tunnel and other model scale results only a meter or so in height represent faithfully the behaviour of structures approaching a 100 stories high.

\section{THE FUTURE OF WIND ENGINEERING}

Wind engineering is a practical field looking for practical answers. It is not merely a catalogue of theoretical ideas. One way to meet this need is through case studies. There exists a number of summaries of real incidents involving wind engineering principles which can be used in an educational context to increase the awareness of important design issues. Examples include the
Tacoma Narrows bridge failure, the Golden Gate bridge, the Ferrybridge cooling towers, the Citicorp building, and so on. These cases could be developed on a cooperative basis.

This paper has stressed other opportunities, one being the adoption of a reliability basis for design. This implies a balance of accuracy and risk and the right emphasis for each link of the "wind loading chain".

Changes in stiffness, mass and damping in structures will lead to new requirements in dealing with wind effects. The exploitation of damping systems would be one timely development in buildings, in cable structures and systems. In aerodynamics we need to confront the Reynolds number effects and Froude number effects which are difficult to model experimentally.

Finally an improved understanding of the effects of climate change and the implication for wind engineering problems is needed to anticipate the future trends of a changing climate. Special consideration is needed to deal with a variety of severe storms, hurricanes, tornadoes, downbursts, thunderstorms and blizzards.

\section{References}

1. Rathbun, J.C., "Wind Forces on Tall Buildings', Transactions of the ASCE, Vol. 105, paper 2056, pp. 1-41, 1940.

2. Spurr, H.V., "Wind Bracing" the Importance of Rigidity in High Towers", McGraw-Hill Book Co., First Edition, N.Y., 1930.

3. Flaschbart, O., "Winddruck auf Bauwerke", Naturwissenschaften, Vol. 18, 1930.

4. Irminger, J.O.V. and Nokkentved, C., "Wind Pressure on Buildings", Experimental Researches ( $2^{\text {nd }}$ Series), No. 42 , Translator A. J. Jarvis, 1936.

5. Bailey, A. and Vincent, N.D.G., "Wind Pressure on Buildings, Including Effects of Adjacent Buildings", J. Inst. Civil Engineers, Vol. 20, No. 8, October 1943, pp. 243-75.

6. Baker, J. R., Horne, M.R. and Heyman, J., "The Steel Skeleton", Cambridge University Press, 1956.

7. Southwell, R.V., "Current Trends in Structural Research", Engineering Structures Colston Papers, University of Bristol, 1949.

8. Taylor, G.I., "Eddy Motion in the Atmospheric”, Phil. Trans. Royal Soc., 1914. 
9. Sutton, O.G., "Atmospheric Turbulence", Methuen, 1949.

10. von Karman, T., "The Wind and Beyond", Little, Brown \& Company, Boston, 1967.

11. Farquharson, F.B., "Aerodynamic Stability of Suspension Bridges", University of Washington Press, 1949.

12. Pugsley, A., "The Theory of Suspension Bridges", Edward Arnold, 1957.

13. Scruton, C. and Frazer, R.A., "A Summarized Account of the Severn Bridge Aerodynamic Investigation", HMSO, 1952.

14. Hirai, A., Okauchi, I. And Miyata, T., "On the Behaviour of Suspension Bridges Under Wind Action", International Symposium on Suspension Bridges, Lisbon, Portugal, November 1966.

15. Hirai, A. and Okubo, T., "On the Design Criteria Against Wind Effects for Proposed Honshu-Shikoku Bridges", International Symposium on Suspension Bridges, Lisbon, Portugal, November 1966.

16. Konishi, I. and Shiraishi, N., "On the Free Vibrational Characteristics of a LongSpanned Suspension Bridge, International Symposium on Suspension Bridges, Lisbon, Portugal, November 1966.

17. Ishizaki, H., "Storm Frequencies and Wind Load Problems", Proceedings of the $3^{\text {rd }}$ International Conference on Wind Effects on Buildings and Structures", Tokyo, Japan, 1971.

18. Vincent, G.S.," "Golden Gate Bridge Vibration Studies", J. Struct. Div., ASCE, Vol. 84, No. ST6, 1817.

19. Richards, D.J.W., "Survey of Aerodynamic Problems in the Electrical Power Supply Industry", J. Roy. Aero. Soc., No. 70, 1966.

20. Jensen, M., "The Model Law for Phenomena in Natural Wind", Reprint from Ingenioren (international edition), Vol. 2, No. 4, pp. 121128, 1958.

21. Ackeret, J., "Der winddruck auf Schornsteine mit Kreisquerschnitt", Schweizer Bauzeirung, 1936.

22. Sherlock, R.H., "Variation of Wind Velocity and Gusts With Height", Trans. ASCE, 1953.

23. Simiu, E. and Scanlan, R.B., "Wind Effects on Structures", John Wiley \& Sons, 1996.

24. Hunt, J.C.R. and Morrison, J.F., "Eddy Structure in Turbulent Boundary Layers",
Eur. J. Mech. B - Fluids 19 (2000) pp. 673694, Elsevier.

25. Davenport, A. G, "The Wind Loading Chain", Prepared for the Application of Wind Engineering Principles to the Design of Structures. A short course taught by A. G. Davenport, B. J. Vickery and J.A. Hertig. Lausanne, Switzerland, February 23-27, 1987. Also from the "Engineering Structures", Development in the Twentieth Century, A collection of essays to mark the eightieth birthday of Sir Alfred Pugsley, Chapter 9, Wind Engineering, Edited by P.S. Bulson, J. B. Caldwell, R.T. Severn, University of Bristol Press, 1983.

26. Davenport, A.G. and King, J.P.C., "The Influence of Topography and Storm Structure on Long Span Bridge Behaviour in Wind", Presented at the Public Works Research Institute, International Seminar on Utilization of Large Boundary Layer Wind Tunnels, December 6-11, 1991, Japan.

27. Davenport, A.G., Isyumov, N. and Miyata, T., "The Experimental Determination of the Response of Suspension Bridges to Turbulent Wind", Proc. $3^{\text {rd }}$ International Conference on Wind Effects on Buildings and Structures, Tokyo, 1971, pp. 1207-1219.

28. Davenport, A.G., King, J.P.C., Kusakabe, T. and Aas-Jakobsen, K., "The Effect of Terrain on the Aerodynamic Response of the Golden Gate Bridge", The University of Western Ontario, Research Report, BLWT-3-1993, October 1993.

29. Tanaka, H. and Davenport, A.G., "WindInduced Response of Golden Gate Bridge", Journal of Engineering Mechanics, Vol. 109, No. 1, February 1983.

30. Davenport, A.G., "The Response and Safety of Tall Buildings in Wind", Presented at the International Conference on Advances in Structural Dynamics (ASD), The Hong Kong Polytechnic University, December 13-15 December 2000, Hong Kong.

\section{Acknowledgements}

Wind engineering is a name suggested by Professor Jack Cermak for the activities related to the impact of wind on engineering and society. The study of wind engineering began at Western about 40 years ago. Throughout this period the 
author has had the inspiration and support of outstanding collaborators who have each made highly significant contributions to the field of wind engineering research. These individuals include Dr. Nick Isyumov, Dr. Barry Vickery, Dr. Dave Surry, and Mr. Peter King, in addition to an exceptionally talented and dedicated technical and administrative staff and student body. The author warmly acknowledges these contributions.

Key words: climate, structural engineering, atmospheric boundary layer, reliability. 